Surgery in the COVID Crisis: Impact on Residency and Training; May 7, 2020.

3. Boskovski MT, Hirji SA, Brescia AA, Chang AC, Kaneko T. Enhancing thoracic surgical trainee competence in the COVID-19 era: challenges and opportunities for mentorship. J Thorac Cardiovasc Surg. 2020;160: 1126-9.

4. Dawes R. The robust beauty of improper linear models in decision making. Am Psychol. 1979;34:571-82.
See Article page 1126.

\section{Commentary: Mentoring trainees when the going gets tough}

Mara B. Antonoff, MD

In their Expert Opinion, Boskovski and colleagues ${ }^{1}$ discuss ways to enhance thoracic surgical trainee competence during the coronavirus 2019 (COVID-19) era. ${ }^{1}$ As has been elaborated by previous authors, this pandemic has changed not only the ways that we live, work, and socialize it has also changed the ways that we, as academic cardiothoracic surgeons, engage in education. ${ }^{2}$ We have entered a time in which we must adapt to the needs of our trainees by developing innovative, collaborative curricular strategies, which carry the potential to improve the efficiency, versatility, and quality of trainees' education long after the pandemic has ended. ${ }^{2,3}$

Boskovski and colleagues ${ }^{1}$ have developed a conceptual framework for quantifying the educational impact of the pandemic on trainees, highlighting the key areas of the COVID-19 burden within the training institution, program case volumes, resident level of training, rotations assigned during the pandemic, and external factors that may impact one's learning. They have reviewed ways to use mentorship to mitigate the negative effects of the pandemic on the future surgeons of our specialty, ranging from junior-level trainees to early-career surgeons. Their proposed ideas include a breadth of

\footnotetext{
From the Department of Thoracic and Cardiovascular Surgery, The University of Texas MD Anderson Cancer Center, Houston, Tex.

Disclosures: The author reported no conflicts of interest.

The Journal policy requires editors and reviewers to disclose conflicts of interest and to decline handling or reviewing manuscripts for which they may have a conflict of interest. The editors and reviewers of this article have no conflicts of interest.

Received for publication June 30, 2020; revisions received June 30, 2020; accepted for publication June 30, 2020; available ahead of print July 13, 2020.

Address for reprints: Mara B. Antonoff, MD, Department of Thoracic and Cardiovascular Surgery, University of Texas MD Anderson Cancer Center, 1515 Holcombe Blvd, Houston, TX 77030 (E-mail: MBAntonoff@mdanderson.org).

J Thorac Cardiovasc Surg 2020;160:1131-2

0022-5223/\$36.00

Copyright (c) 2020 by The American Association for Thoracic Surgery

http://dx.doi.org/10.1016/j.jtcvs.2020.06.112
}

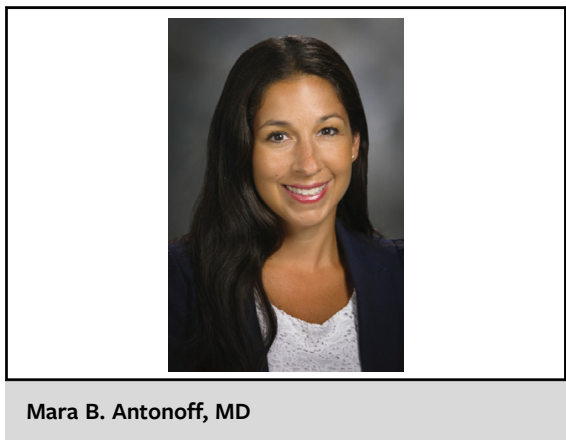

CENTRAL MESSAGE

Mentorship is key to supporting trainees through the curricular challenges of a pandemic; more importantly, mentorship is crucial to navigating heightened external challenges during this time.

approaches such as teaching decision making via telehealth, promoting academic success through remote research opportunities, and using simulation to enhance technical skills. This article focuses expertly in these areas; nevertheless, it is critical that we stay simultaneously attuned to the fact that there are additional areas of mentoring needs for our trainees during this crisis.

As we consider the impact of the pandemic on a training environment and its ability to enable acquisition of knowledge and technical skills by trainees, it is clearly enormous. ${ }^{2}$ Such in-hospital issues may pale, however, compared with those that occur outside of the training environment-yet still impact training. These additional influences on trainees' ability to learn during the pandemic include the trainees' personal health, whether they have been out of work (either ill with COVID-19 or quarantining due to exposure or family illness), and the detrimental influence of family needs on time to study at home. Moreover, and perhaps even of greater importance, is the fact that trainees may also be balancing direct these educational issues with finding food for one's family, caring for aging parents, 
weathering financial losses and/or loss of partners' jobs, or facilitating distance learning for school-aged children.

Issues of work-life integration are of substantial constitutive need when it comes to mentoring trainees, even during normal times, as they navigate concerns of family planning, childbearing, and childrearing. ${ }^{4}$ In a pandemic, such everyday work-life balance questions are further amplified. Beyond these anxiety-provoking stressors, trainees may be suffering from other challenges to their mental health, including depression, heightened risk for addiction, grief, and posttraumatic stress. Outside of a pandemic, when it comes to overcoming adversity during training, it has been shown that personal connections to mentors can help buffer the stress and conflicts faced. ${ }^{5,6}$ During times such as these, certainly, the empathy, guidance, and problem-solving support of mentors can be crucial. We can address both the educational and external needs of trainees by providing accessibility, attentiveness, and emotional support. ${ }^{6}$

Boskovski and colleagues ${ }^{1}$ have done a tremendous job of laying a foundation for how we can use mentorship models to support the education of the cardiothoracic surgical workforce during this demanding time. While our trainees desperately need us to mentor them through the curricular challenges of a pandemic, they also need-now more than ever-our mentorship through these life challenges.

\section{References}

1. Boskovski M, Hirji S, Brescia A, Chang A, Kaneko T. Enhancing thoracic surgical trainee competence in the COVID-19 era: challenges and opportunities for mentorship. J Thorac Cardiovasc Surg. 2020;160:1126-9.

2. Lewis EE, Taylor LJ, Hermsen JL, McCarthy DP, Fiedler AG. Cardiothoracic education in the time of COVID-19: how I teach it. Ann Thorac Surg. 2020;110: 362-3

3. Luc JGY, Antonoff MB. Necessity is the mother of innovation-the time to collaborate is now. Ann Thorac Surg. April 10, 2020 [Epub ahead of print].

4. Corsini EM, Antonoff MB. Mentorship: vital to women on both sides of the relationship. Available at: https://blog.womensurgeons.org/mentorship/mentorshipvital-to-women-on-both-sides/. Accessed July 17, 2020.

5. Winkel AF, Honart AW, Robinson A, Jones AA, Squires A. Thriving in scrubs: a qualitative study of resident resilience. Reprod Health. 2018;15:53.

6. Odell D, Edwards M, Fuller S, Loor G, Antonoff M. The art and science of mentorship in cardiothoracic surgery: a systematic review of the literature. Ann Thorac Surg [In press]. 